\title{
Distilling the role of ecosystem services in the Sustainable Development Goals
}

\section{Sylvia L.R. Wood ${ }^{\mathrm{a}, \mathrm{d}, *}$, Sarah K. Jones ${ }^{\mathrm{a}, \mathrm{b}}$, Justin A. Johnson ${ }^{\mathrm{c}}$, Kate A. Brauman ${ }^{\mathrm{c}}$, Rebecca Chaplin-Kramer ${ }^{\mathrm{e}}$, Alexander Fremier ${ }^{\mathrm{f}}$, Evan Girvetz ${ }^{\mathrm{g}}$, Line J. Gordon ${ }^{\mathrm{h}}$, Carrie V. Kappel ${ }^{\mathrm{i}}$, Lisa Mandle ${ }^{\mathrm{e}}$, Mark Mulligan ${ }^{\mathrm{b}}$, Patrick O’Farrell ${ }^{\mathrm{j}}$, William K. Smith ${ }^{\mathrm{k}}$, Louise Willemen ${ }^{\mathrm{l}}$, Wei Zhang ${ }^{\mathrm{m}}$, Fabrice A. DeClerck ${ }^{\mathrm{a}, \mathrm{h}}$}

a Bioversity International, CGIAR, Montpellier, France

${ }^{\mathrm{b}}$ Department of Geography, King's College London, London, UK

'Institute on the Environment, University of Minnesota, St. Paul, USA

${ }^{\mathrm{d}}$ Columbia University Earth Institute Center on Environmental Sustainability, New York, USA

e Natural Capital Project, Stanford University, Stanford, CA, USA

${ }^{\mathrm{f}}$ School of the Environment, Washington State University, Pullman, WA, USA

${ }^{\mathrm{g}}$ International Center for Tropical Agriculture, Nairobi, Kenya

${ }^{\mathrm{h}}$ Stockholm Resilience Center, Stockholm University, Stockholm, Sweden

${ }^{\mathrm{i}}$ National Center for Ecological Analysis and Synthesis, Santa Barbara, CA, USA

${ }^{\mathrm{j}}$ Council for Scientific and Industrial Research, South Africa

${ }^{\mathrm{k}}$ School of Natural Resources and the Environment, University of Arizona, Tucson, AZ, USA

${ }^{1}$ Faculty of Geo-information Science and Earth Observation (ITC), University of Twente, Enschede, The Netherlands

${ }^{\mathrm{m}}$ International Food Policy Research Institute, CGIAR, Washington, DC, USA

\section{A R T I C L E I N F O}

\section{Article history:}

Received 16 January 2017

Received in revised form 9 October 2017

Accepted 16 October 2017

Available online 1 December 2017

\section{Keywords:}

Environmental benefits

Sustainable Development Goals

Interactions

Ecosystem modelling

Policy review

\begin{abstract}
A B S T R A C T
Achieving well-being for all, while protecting the environment, is one of the most pressing global challenges of our time, and a central idea in the UN Sustainable Development Goals (SDGs). We believe that integrating ecosystem services, the benefits nature provides to people, into strategies for meeting the SDGs can help achieve this. Many development goals are likely underpinned by the delivery of one or more ecosystem services. Understanding how these services could support multiple development targets will be essential for planning synergistic and cost-effective interventions. Here we present the results of an expert survey on the contributions of 16 ecosystem services to achieving SDG targets linked to environment and human well-being, and review the capacity of modelling tools to evaluate SDG-relevant ecosystem services interactions. Survey respondents judged that individual ecosystem services could make important contributions to achieving 41 targets across 12 SDGs. The provision of food and water, habitat \& biodiversity maintenance, and carbon storage \& sequestration were perceived to each make contributions to $>14$ SDG targets, suggesting cross-target interactions are likely, and may present opportunities for synergistic outcomes across multiple SDGs. Existing modelling tools are well-aligned to support SDG-relevant ecosystem service planning. Together, this work identifies entry points and tools to further analyze the role of ecosystem services to support the SDGs.
\end{abstract}

(c) 2017 Elsevier B.V. All rights reserved.
* Corresponding author at: Institut des sciences de la forêt tempérée, Université de Québec en Outaouais, 58 rue Principale, Ripon, QC., J0V 1V0, poste 2931, Canada.

E-mail addresses: sylvia.wood@mail.mcgill.ca (S.L.R. Wood), s.jones@cgiar.org (S.K. Jones), Joh07536@umn.edu (J.A. Johnson), kbrauman@umn.edu (K.A. Brauman), bchaplin@stanford.edu (R. Chaplin-Kramer), alex.fremier@wsu.edu (A. Fremier), egirvetz@cgiar.org (E. Girvetz), line.gordon@stockholmresilience.su.se (L.J. Gordon), kappel@nceas.ucsb.edu (C.V. Kappel), lmandle@stanford.edu (L. Mandle), mark. mulligan@kcl.ac.uk (M. Mulligan), POFarrell@csir.co.za (P. O’Farrell), wksmith@ email.arizona.edu (W.K. Smith), 1.l.willemen@utwente.nl (L. Willemen),w.zhang@ cgiar.org (W. Zhang), f.declerck@cgiar.org (F.A. DeClerck).

\section{Introduction}

With the formal adoption of the UN Sustainable Development Goals (SDGs) and their launch in 2016, governments globally are tasked with developing pathways to achieve nationally prioritized targets that incorporate social, economic and environmental dimensions of sustainability, moving beyond sectoral approaches of the past. Building on progress made under the UN Millennium Development Goals (UN, 2015a), the SDGs are a globally agreed upon set of 17 goals, 169 nested targets, and over 200 associated 
indicators that set the agenda for addressing sustainable development challenges by 2030. Yet, practical strategies for achieving these aims in unison, particularly how ecosystems can be both protected and managed to support human well-being objectives, are not specified and present important and urgent research questions.

The wide range of themes incorporated into the SDGs, from poverty and hunger alleviation to sustainable cities, economies, and ecosystems (see Table 1) point to their ambition to improve the lives of the world's poorest and most marginalized communities through a multi-sectoral approach. Embedded in the goals is an aim to rebuild and strengthen the integrity and function of ecosystems to secure the benefits they provide to both current and future generations (UN, 2015b; UN Secretary-General, 2014). In order for the SDGs to be achieved, national strategies must be built on sound science and engagement of local stakeholders (Griggs et al., 2014; LPFN, 2015; Mbow et al., 2014), and they must be sensitive to inherent interactions across goals and targets (ICSU ISSC, 2015; Nilsson et al., 2016).

Biodiversity, ecosystems and the services they provide underpin all dimensions of human, societal, cultural and economic wellbeing (Folke et al., 2016; MEA, 2005; Naeem et al., 2012). However, much of human economic and social development has come through the unsustainable exploitation of ecosystems (MEA, 2005; Raudsepp-Hearne et al., 2010a), with society approaching or already surpassing a number of planetary boundaries (Steffen et al., 2015). Despite intensive use of many ecosystems and substantial improvements in many aspects of development over the past century (UNDP, 2015), human well-being has yet to reach a minimum acceptable level for all people worldwide (Raworth, 2012). An estimated 795 million people remain undernourished (FAO, 2015), and access to education, health, employment and wealth is distributed highly unevenly across societies (UNDP, 2015; World Economic Forum, 2016). To realize the ambitions embodied in the SDGs, it will be essential to manage ecosystems to protect nature and the sustainable supply of, as well as equitable access to, the benefits and services they provide (DeClerck et al., 2016). Such efforts should increasingly be informed by regional, global and thematic assessment work that is currently being undertaken by the Intergovernmental Panel on Biodiversity and Ecosystem Services (IPBES), amongst others.

Numerous articles have highlighted the importance of integrating environmental science into decision-making processes for the SDGs (ICSU ISSC, 2015; Norström et al., 2014; Rockström and Falkenmark, 2015; Stafford-Smith, 2014; Wood and DeClerck, 2015) and for understanding interactions between distinct sustainability targets (ICSU ISSC, 2015; Nilsson et al., 2016). According to a review of the targets and goals by the International Council for Science (ICSU ISSC, 2015), all SDG goals benefit to some degree from ecosystem protection, restoration and sustainable use. Sound ecological management is required not just to constrain the environmental costs of meeting development these goals, but also to enhance and sustain flows of ecosystem services to humanity. Achievement of higher order social and economic goals is dependent on a healthy biosphere (Folke et al., 2016).

For policy makers to embrace a development approach where the environment (i.e. natural capital) is managed to achieve multiple objectives, there must be a sound understanding of how the services provided by nature can contribute to individual or multiple SDG targets. It will be important for landscape managers implementing policy directives to know how these services are produced and affected by human activities across their landscapes to effectively manage for them. Over the past two decades, significant progress has been made to identify ways in which ecosystems benefit people and on the feedbacks between management actions and their impacts on single and bundles of ecosystem services (Díaz et al., 2015; Maes et al., 2012; Raudsepp-Hearne et al., 2010b; Renard et al., 2015). Synthesizing this knowledge in the context of the SDGs, at this early point in their uptake, will help define a path forward on how best make use of the current knowledge of ecosystem services to achieve targets under the UN directive for a holistic approach (UN, 2015b), as well as to identify opportunities for cross-sectoral collaborations for addressing interrelated SDGs.

Similarly, rapid progress has been made over the past decade on evaluating and integrating ecosystem services into landscape planning with the emergence of modelling tools and high-resolution spatial datasets. Ecosystem service models provide important tools

Table 1

Sustainable Development Goals and the selected targets evaluated in the expert survey (see details on targets in SM1).

\begin{tabular}{|c|c|c|c|}
\hline SDG & Title & Goal & Evaluated Targets \\
\hline SDG1 & No Poverty & End poverty in all its forms everywhere & $1.1,1.2,1.5$ \\
\hline SDG2 & Zero Hunger & $\begin{array}{l}\text { End hunger, achieve food security and improved nutrition and promote } \\
\text { sustainable agriculture }\end{array}$ & $2.1,2.2,2.3,2.4,2.5$ \\
\hline SDG3 & Good Health \& Well-Being & Ensure healthy lives and promote well-being for all at all ages & $3.3,3.4,3.9$ \\
\hline SDG4 & Quality Education & $\begin{array}{l}\text { Ensure inclusive and equitable quality education and promote lifelong learning } \\
\text { opportunities for all }\end{array}$ & \\
\hline SDG5 & Gender Equity & Achieve gender equality and empower all women and girls & \\
\hline SDG6 & Clean Water \& Sanitation & Ensure availability and sustainable management of water and sanitation for all & $6.1,6.3,6.4,6.6$ \\
\hline SDG7 & Affordable \& Clean Energy & Ensure access to affordable, reliable, sustainable and modern energy for all & $7.1,7.2$ \\
\hline SDG8 & Decent Work \& Economic Growth & $\begin{array}{l}\text { Promote sustained, inclusive and sustainable economic growth, full and } \\
\text { productive employment and decent work for all }\end{array}$ & $8.2,8.4,8.9$ \\
\hline SDG9 & Industry, Innovation \& Infrastructure & $\begin{array}{l}\text { Build resilient infrastructure, promote inclusive and sustainable } \\
\text { industrialization and foster innovation }\end{array}$ & $9.1,9.4$ \\
\hline SDG10 & Reduced Inequality & Reduce inequality within and among countries & \\
\hline SDG11 & Sustainable Cities \& Communities & Make cities and human settlements inclusive, safe, resilient and sustainable & $11.5,11.6,11.7,11 . a, 11 . c$ \\
\hline SDG12 & Responsible Production \& Consumption & Ensure sustainable consumption and production patterns & $12.2,12.3,12.4,12.5$ \\
\hline SDG13 & Climate Action & Take urgent action to combat climate change and its impacts & 13.1 \\
\hline SDG14 & Life Below Water & $\begin{array}{l}\text { Conserve and sustainably use the oceans, seas and marine resources for } \\
\text { sustainable development }\end{array}$ & $\begin{array}{l}14.1,14.2,14.3,14.14,14.5 \\
14.7\end{array}$ \\
\hline SDG15 & Life on Land & $\begin{array}{l}\text { Protect, restore and promote sustainable use of terrestrial ecosystems, } \\
\text { sustainably manage forests, combat desertification, and halt and reverse land } \\
\text { degradation and halt biodiversity loss }\end{array}$ & $15.1,15.2,15.3,15.4,15.5,15.8$ \\
\hline SDG16 & Peace, Justice \& Strong Institutions & $\begin{array}{l}\text { Promote peaceful and inclusive societies for sustainable development, provide } \\
\text { access to justice for all and build effective, accountable and inclusive } \\
\text { institutions at all levels }\end{array}$ & \\
\hline SDG17 & Partnerships for the Goals & $\begin{array}{l}\text { Strengthen the means of implementation and revitalize the Global Partnership } \\
\text { for Sustainable Development }\end{array}$ & \\
\hline
\end{tabular}


to facilitate national and regional decision-making by assessing service trade-offs and synergies across multiple sectors under diverse management scenarios (e.g. Guerry et al., 2015; Mulligan, 2015; Ruckelshaus et al., 2015; Villa et al., 2014), moving away from single-goal oriented approaches. IPBES has recently led efforts to review and summarize existing modelling tools to guide their use in regional, global and thematic assessments as well as outlining best-practices for policy-makers in the use of these tools (Ferrier et al., 2016). However, guidance on how and when ecosystems and their services can be managed to deliver on specific and/ or multiple human development targets remains poorly articulated and difficult for policy-makers to incorporate into national development plans.

The goal of this paper is to summarize current understandings on the potential role of ecosystem services to contribute to the SDGs and thereby outline a path forward for their incorporation into national SDG policy considerations and landscape planning. We consulted ecosystem service and development experts via a survey on their perceptions of the contribution of 16 individual ecosystem services to SDG targets. We use information gathered through this survey and a review of current modelling tools to address the following questions: (i) what are expert perceptions regarding potential of ecosystem services to contribute to attainment of the SDGs?; (ii) where are cross-target or cross-goal interactions likely to occur based on these perceptions?; and (iii) are current modelling tool capacities adequately aligned to support landscape planning around these interactions?

\section{Materials and methods}

\subsection{ES-SDG linkages}

We conducted an anonymous online survey to evaluate linkages between SDG targets and 16 specific ecosystems services taken from the TEEB ecosystem services typology (TEEB 2010, Table 2). The 16 selected ecosystem services include provisioning, regulating, supporting and cultural services. An online survey tool (SurveyMonkey) was used to create the survey and was sent out from April 29th to May 30th, 2016 through academic and professional listservs to ecosystem service experts. A second round of the survey was conducted from March 15th to March 23rd, 2017 with the aim of broadening the profile of respondents to include greater representation from development and practitioner communities. Contacted organizations include the network mailing lists of: Ecosystem Services Partnership (ESP), The Economics of Ecosystems and Biodiversity (TEEB), Intergovernmental Panel on Biodiversity and Ecosystem Services (IPBES), Ecological Society of America (ECOLOG), CGIAR Water Land Ecosystems and its program partners, CGIAR Ecosystem Services and Resilience, UN Sustainable Development Solutions Network (SDSN), Natural Capital Project, Institute International Sustainable Development, Science for Nature and People Partnership (SNAPP) working group members involved in this study, as well as directed emails to researcher and practitioners in the field (for a full list of contacted organizations see SM2). We used a snowball technique to increase participation, asking respondents to forward the survey to qualified colleagues. This is a non-probability approach, and thus we rely on descriptive rather than statistical analysis of the collected data.

Survey respondents were asked to identify their highest academic qualification, institutional affiliation type, discipline or area of expertise, landscape of expertise and their number of years experience ( $<1$ year, $1-5$ years, $5-10$ years, $>10$ years) working on ecosystem services (round 1) or development issues (round 2). Respondents in the second survey round were additionally asked to identify the use of ecosystem service concepts in their work
Table 2

The 16 ecosystem services included in the expert survey modified from the original 22 TEEB ecosystem services typology.

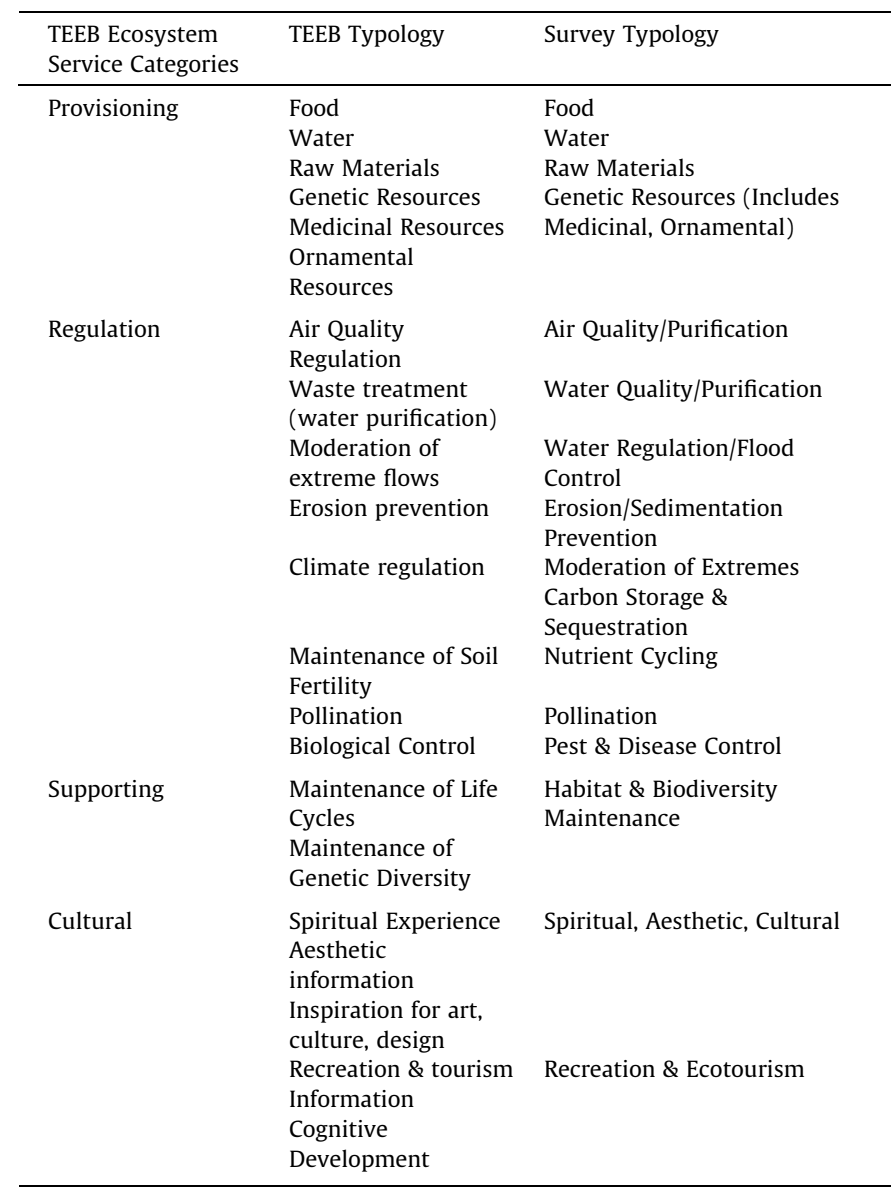

from 'Never, Rarely, Occasionally' to 'Frequently'. We only consider respondents with a reported academic degree and/or more than one year of experience with ecosystem services (round 1) or development (round 2) to ensure minimum qualifications to be considered an expert. We further exclude respondents in round 2 who 'Never' or 'Rarely' used ecosystem service concepts, as we consider these respondents less likely to provide informed responses on the roles of ecosystem services in the SDGs. Full copies of the survey tools can be found in the Supplementary Material (SM3).

The survey aimed to gather expert views on, primarily, whether good management of each of the 16 ecosystem services could contribute to specific SDG targets, and, secondarily, how important these ecosystem service flows are to achieving the SDG target in question (see SM3 for copy of the survey). A wide range of practices can be considered "good management" (for instance optimization for a single service at the expense of others) and this may vary with socio-ecological context. We intentionally used the term "good management" in the phrasing of the question to allow for individual interpretation by experts. We requested that respondents choose up to three ecosystem services in line with their expertise and evaluate their potential contribution to targets under one to two SDG goals they felt competent to assess. For each selected ecosystem service-SDG target combination (ES-T), respondents were asked i) if they 'Agreed', 'Disagreed' or 'Didn't know' whether good management of the selected ecosystem service could directly or indirectly help to attain the stated target; ii) to rank the importance of the ecosystem service contribution to target achievement on a four-point scale from 'Not important' to 'High'; and iii) to assess confidence in their own evaluation of this 
ES-T relationship on a five-point scale from 'Very Low' to 'Very High'. Median responses were used in the analysis of these data.

Due to the large number of SDG targets $(n=169)$, we reduced the number included in the survey by excluding those targets for which there was no clear environmental link (e.g. reducing substance abuse or improving access to reproductive health-care services) and policy-oriented targets (e.g. new laws or financial mechanisms; see SM1 for list of included and excluded targets). This left 44 targets across 12 SDGs for consideration (Table 1 ). Linkages between ecosystem services and the 125 excluded SDG targets may exist but were not evaluated here.

We identify ES-T combinations with perceived support from pooled survey responses (an analysis treating each survey round independently is found in SM5). By "support" we mean that multiple experts judged an ecosystem service could positively contribute to a target, and that the experts were confident in their assessments. Our criteria for levels of support were as follows: "strong" expert support was defined as ES-T combinations that: i) were evaluated by more than five respondents, ii) of which more than $75 \%$ agreed that the ecosystem service could contribute positively to the target, and iii) the median ranked confidence in this assessment was 'High' or above. Those ES-T combinations with fewer than five responses or where only $50-75 \%$ of experts responded that there could be a positive contribution were classified as having insufficient or "weak" expert support and were not considered further in our analysis. We also excluded combinations where less than $50 \%$ of respondents judged good management of the ecosystem service to contribute to attainment of the target as they were considered to have "uncertain" or no support from experts.

Of the ES-T combinations classified by the authors as having strong expert support, we highlight those combinations where the median response to the question on the importance of the ecosystem service contribution to target attainment was ranked as 'High' as focal points for policy action. We focus on these "High importance"ES-T combinations because decisions affecting such services are expected, based on expert response, to have the greatest potential impact on SDG outcomes. Finally, we tabulate the cooccurrence of expert supported ecosystem services contributions to common targets to detect likely points of cross-service and cross-target interactions, i.e. where potential exists for synergies and trade-offs. We used the program Gephi v3 0.9.1 (Bastian et al., 2009) to create bipartite network diagrams to visualize these ecosystem service contributions of "High importance" to each of the assessed SDG targets.

\subsection{Review of modelling tools for evaluating ES-SDG linkages}

We reviewed current ecosystem service modelling tools to assess their capacity to inform ecosystem service provision and interactions important to SDGs identified from the survey results. To identify ecosystem service models commonly in use, we searched Google Scholar for articles with the following key search terms, individually or in combination, *ecosystem, *ecosystem service, $*$ modelling, as well as individual ecosystem service names, coupled with $*$ terrestrial and $*$ urban. We included only articles published before April 1st, 2016. We reviewed the cited references in these papers for additional modelling tools and followed up with targeted web searches to identify tool platforms, applications and documentation. We searched United States Environmental Protection Agency's online EcoService Model Library and GIZ's ValuES portal to identify additional modelling tools. To be included in our review, tools needed to: i) address more than a single ecosystem service at the landscape-level or larger (so as to be relevant for trade-off assessments), ii) be a publically accessible 'off-the-shelf' tool and not a proprietary product, iii) not be tied to a specific geographic location or landscape (e.g. Vermont forests), and iv) be spatially explicit. For models meeting these criteria we reviewed their stated capacity to evaluate the 16 ecosystem services included in the expert survey. In addition, tools were classified as ecosystem process, ecosystem service, or integrated assessment models. 'Ecological process' tools are those able to evaluate ecological functions and drivers that underpin ecosystem service provision (e.g. soil erosion, infiltration, pollination) but require post-processing to evaluate an ecosystem service (i.e. human benefit) (Vigerstol and Aukema, 2011); 'ecosystem service' tools connect an ecosystem function to a real or estimated local population benefit; finally 'integrated assessment models' are tools which couple multiple ecological, social and/or economic sub-models to predict changes in ecosystem function, services and/or economy resulting from policy outcomes (Jakeman and Letcher, 2003). For each we also recorded their method of analysis (i.e. statistical, process-based, Bayesian, optimization), focal biome, ability to estimate service delivery or demand, economic valuation approach and ease of use. A list of all models, criteria and references for each model are provided in Supplementary Material (SM4).

\section{Results}

\subsection{Survey results}

\subsubsection{Summary of survey responses}

In the first survey round, 328 individuals participated, of whom 169 provided opinions on the contribution of at least one ecosystem service to one SDG target. In the second survey round, aimed to reach additional experts in development communities, 231 individuals initiated the survey and 123 completed at least one ecosystem service - target (ES-T) evaluation. In total, this translated into 3281 and 2550 unique ES-T evaluations completed by respondents in the two surveys rounds.

\subsubsection{Profile of survey respondents}

Based on descriptive qualities provided by respondents, the two survey rounds reached a broad array of ecosystem service and development experts. Respondents spanned the five major continents with $27 \%$ of respondents from North America, 22\% Europe, $17 \%$ Asia, and $\sim 10 \%$ from both Latin America and Africa. Experts worked in a mix of institutional settings (14\% research, $14 \%$ government, $16 \%$ non-government, $10 \%$ international organizations and $8 \%$ private), with slightly greater representation from academic institutions (33\%). The majority of respondents held a masters or doctoral degree (40\% and $47 \%$, respectively) with 5 to 10 or more years of experience ( $19 \%$ and $43 \%$, respectively). Only $3 \%$ of respondents indicated no degree and $3.5 \%$ had less than one year of experience or provided no indicated experience and were excluded in the analysis. Across the surveys, respondents predominantly worked within agriculture, ecology, natural resource management sectors though many also worked in interdisciplinary and sustainability sciences (SM5.1 for detailed respondent group profiles). The profile of survey respondents who initiated but did not complete the surveys had very similar distributions of background and institutional traits as those completing the survey (See SM5.2). Survey data were pooled across the two rounds in subsequent analyses.

\subsubsection{Ecosystem Service-SDG target evaluation rate}

Respondents' evaluations were unevenly distributed across SDG goals and across ecosystem services. While almost all possible ecosystem service-target (ES-T) contributions were evaluated at least once, the distribution of responses was skewed towards 
SDG1 No Poverty, SDG2 Zero Hunger, SDG6 Clean Water, and SDG15 Life on Land (SM6.1). The most frequently evaluated services were provision of food and water, habitat \& biodiversity maintenance, and water quality services. Despite the high number of respondents pooled across both surveys, several ecosystem services were only selected for evaluation by a small number of experts $(\mathrm{n}<30)$, including air quality, raw materials, genetic resources, pest \& disease control, and pollination services, suggesting that these services may not have been adequately evaluated to identify all potential linkages. Because of the low response rate for these ES-T combinations, many failed to meet our minimum threshold of five evaluations and were excluded from further evaluation, potentially under-representing the contribution these services could make towards the SDGs. Possible explanations for low response rates for these services include i) low familiarity or fewer people working on the service, ii) low perceived importance or priority relative to other ecosystem services, or iii) the length of the survey and limit of selecting only three services to evaluate.

\subsubsection{Expert perceptions of ecosystem service contribution to SDG targets}

From a total of 704 potential ES-T combinations, there was strong expert support for 231 unique combinations. The majority of remaining ES-T combinations evaluated $(n=364)$ were classified as having weak or insufficient support, primarily because they had less than five evaluations, rather than due to low agreement or confidence. In these cases, support regarding the existence or importance of ES-T interactions is considered to be too weak for inclusion in the analysis. Fourteen ES-T interactions received more than 5 responses but less than $50 \%$ agreement that the ecosystem service in question would contribute to target attainment; these were considered to have uncertain support and a further 95 ES-T interactions were not assessed.

\subsubsection{Perceived importance of ecosystem service - target contributions}

Although Fig. 1 illustrates areas where experts perceived ecosystem services to make a contribution, respondents did not rate all contributions with equal importance for SDG target attainment. Amongst the 231 ES-T combinations with strong expert support, 178 were perceived to have 'High' importance for the attainment of the target. For 41 of the 44 assessed SDG targets, at least one ecosystem service was considered to be of 'High' importance for attainment of the target (Fig. 2). Of the 12 SDGs considered in the survey, SDG2 Zero Hunger, SDG14 Life Below Water and SDG15 Life on Land, had the most number of targets thought to depend up on ecosystem service contributions. Similarly, ecosystem services were judged to make important contributions to $40-50 \%$ of targets under SDG6 Clean Water and SDG11 Sustainable Cities. In subsequent sections we focus on only these ES-T contributions of 'High' perceived importance.

\subsubsection{Network analyses of important ecosystem service contributions to targets}

We used a bipartite network analysis to plot the 178 ES-T interactions of 'High' perceived importance by each SDG target (Fig. 3). In the pooled surveys, provision of food and water and habitat \& biodiversity maintenance services were the most frequently evaluated and also perceived as contributing to the greatest number of distinct targets (21, 21 and 26 targets respectively) followed by carbon storage \& sequestration (14). Water quality, water regulation, raw material provisioning and recreation \& tourism each contributed to 10 or more targets. Goals SDG1 No Poverty, SDG2 Zero Hunger, SDG6 Clean Water and SDG15 Life on Land were thought to receive the greatest number of distinct ecosystem services con- tributions, with 5, 12, 7 and 14 ecosystem services contributing to targets within each SDG respectively (Fig. 3 and Fig. 4).

\subsubsection{Poverty-agriculture-water-nature nexus - Opportunities for synergies?}

To draw out potential interactions and opportunities for synergies across perceived ES-T contributions, we plotted the network diagram of ecosystem service contributions identified by experts for the most highly connected goals: SDG1 No Poverty, SDG2 Zero Hunger, SDG6 Clean Water and SDG15 Life on Land targets (Fig. 4). While many of the services were thought to contribute to at least two goals, food provision, water provision, and habitat \& biodiversity maintenance were perceived as central to all four goals. These three services represent potentially important interaction spaces for trade-offs or synergies across services and policy makers may need to consider these services in tandem for the attainment of these four SDGs in concert.

3.1.8. Anticipated interactions among ecosystem services for the SDGs

Results from surveyed experts suggest that at least one ecosystem service was deemed important for the attainment 41 of the 44 targets and many targets were thought to receive important contributions from two or more services (Fig. 2b). When designing interventions around targets underpinned by multiple services it will be critical to assess and predict how landscape decisions change the provision of each service to identify cost-effective and synergistic solutions. Interventions designed to address one target by increasing supply of a single ecosystem service (e.g. tree planting to increase carbon sequestration) may cause an increase in a second (i.e. synergies, e.g. erosion control) but declines in a third (i.e. trade-offs, e.g. reduced food production). In order to understand which combinations of services will most frequently need to be managed in concert when tackling the SDGs we tabulated the total number of pair-wise sets of ecosystem services perceived to contribute to individual targets across all SDG goals (Fig. 5a). The most common combinations of services involved food and water provision and habitat \& biodiversity maintenance together and in combination with most regulating ecosystem services except for pest \& disease control and air quality which had few cooccurences with other services. Spatial models that estimate both overall direction (i.e. increase or decrease) as well as spatial variation in the provision of multiple services can help landscape planners to predict the outcomes of proposed interventions on communities across the landscape and reduce potential negative trade-offs.

\subsection{Modelling tool review}

\subsubsection{Modelling tool capacities}

Our Internet search identified 67 modelling tools addressing ecosystem processes and services. Of these, 42 were excluded from our assessment because they were either under proprietary rights, single ecosystems service models, conceptual assessment frameworks, under development, or no longer in use. This left 23 modelling tools accessible to policy-makers and potentially capable of assessing trade-offs in ecosystem functions or services at the landscape scale or larger (Table 3 ).

Most of the tools evaluated did not incorporate the capacity to dynamically assess synergies or trade-offs between multiple services, rather users can combine model outputs for a number of ecosystems services post hoc to assess trade-offs. At the time of review, the modelling tools examined produce outputs for, on average, seven of the 16 ecosystem services considered in our assessment (Table 3), however some models may have since evolved to include more services (e.g. Co\$tingNature). Reviewed models most commonly provided the option to assess the follow- 


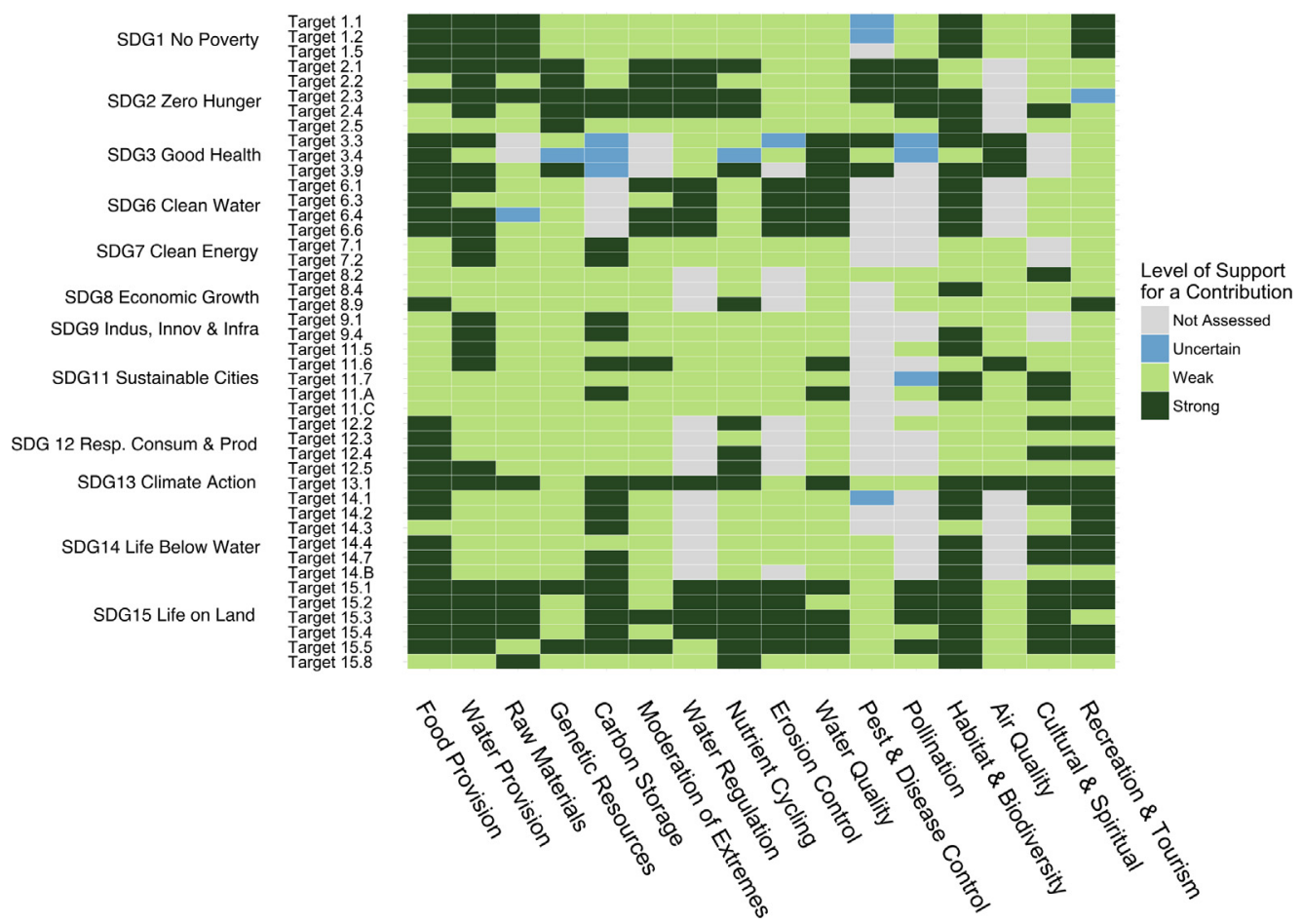

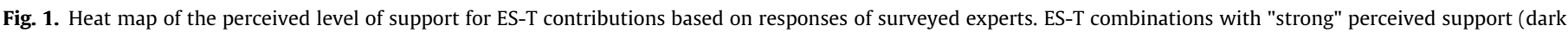

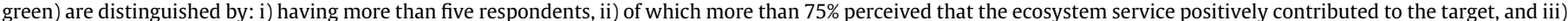

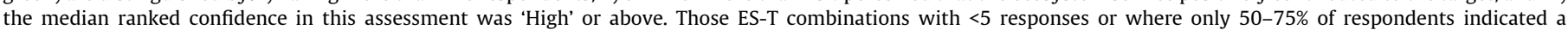

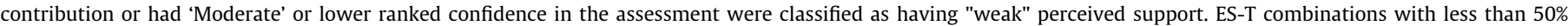

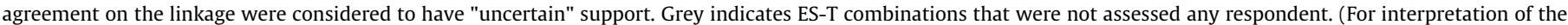
references to colour in this figure legend, the reader is referred to the web version of this article.)
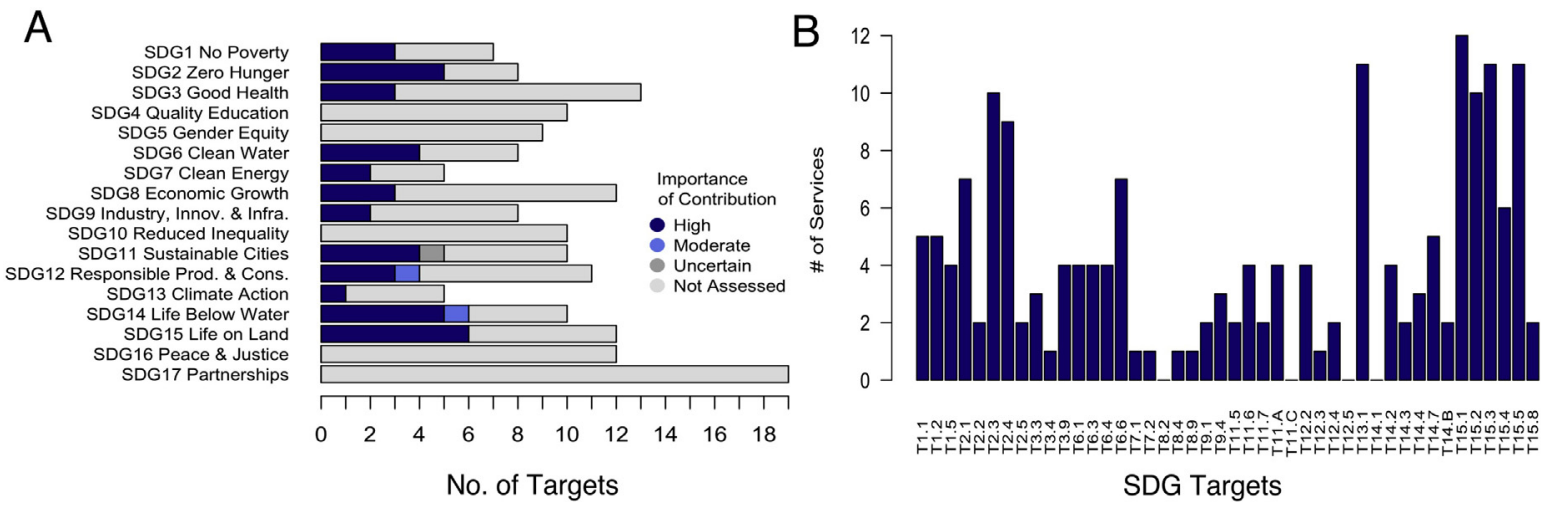

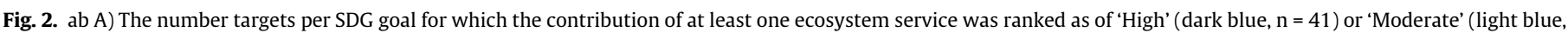

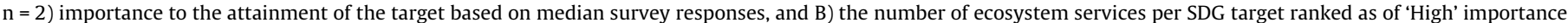

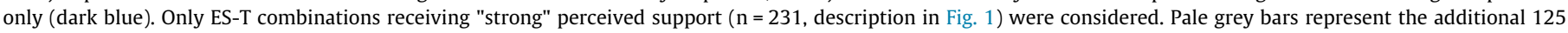

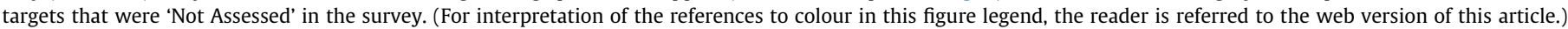

ing ecosystem services: water provisioning ( $\mathrm{n}=19$ models), carbon storage \& sequestration (17), food provision (16), nutrient cycling (14), water quality (14), and erosion control (14). Fewer models provide options to assess moderation of extremes (5), pest \& disease control (4), pollination (3), or air quality (2), nd none for genetic resource provisioning. Cultural services were separated into 'cultural and spiritual', 'aesthetic', and 'recreation and tourism' for which a moderate number of tools $(n=5-8)$ were available (Table 3).

Comparing the capacity tools to assess all 16 ecosystem services, we determined which pair-wise sets of ecosystem service most commonly co-occur within single modelling tools and thus can assess synergies and trade-offs between them (Fig. 5b). The majority of tools evaluated are capable of producing spatiallyexplicit outputs assessing co-occurrence of food and water provisioning, carbon storage \& sequestration and nutrient cycling services. In particular, water provisioning and carbon storage \& sequestration services have the greatest number of tools capable of offering estimates of both $(n=15)$, followed closely by water provision - erosion control $(n=14)$, water provision - food provision $(n=12)$, and water provision - water quality $(n=12)$. As well there were a large number of tools to evaluate habitat \& biodiversity maintenance - cultural, spiritual \& aesthetic $(n=13)$ service interactions. A smaller number of tools ( $<8$ models) were collec- 


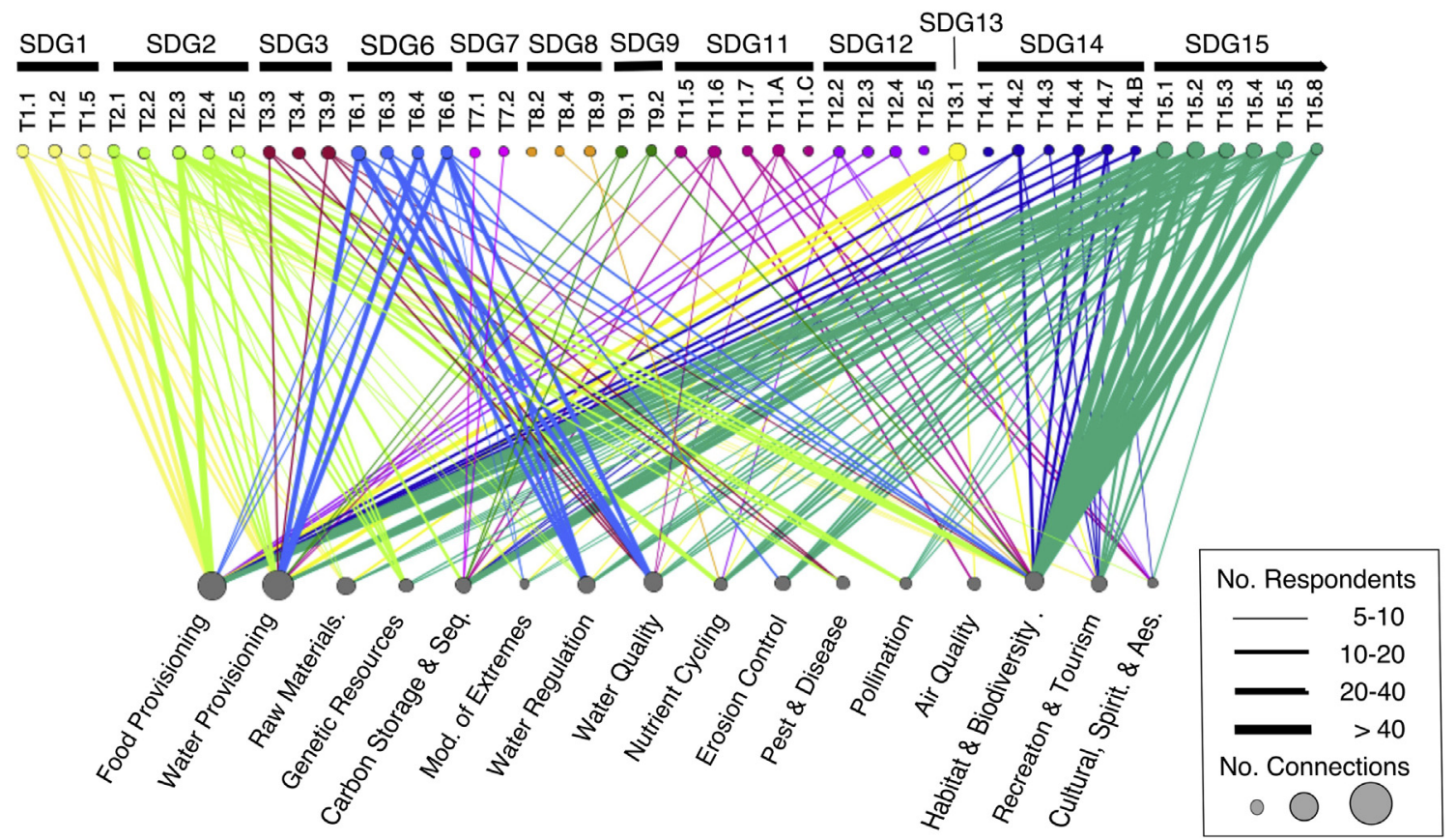



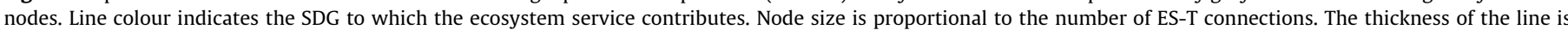

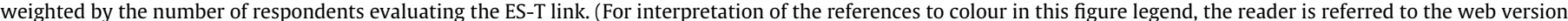
of this article.)

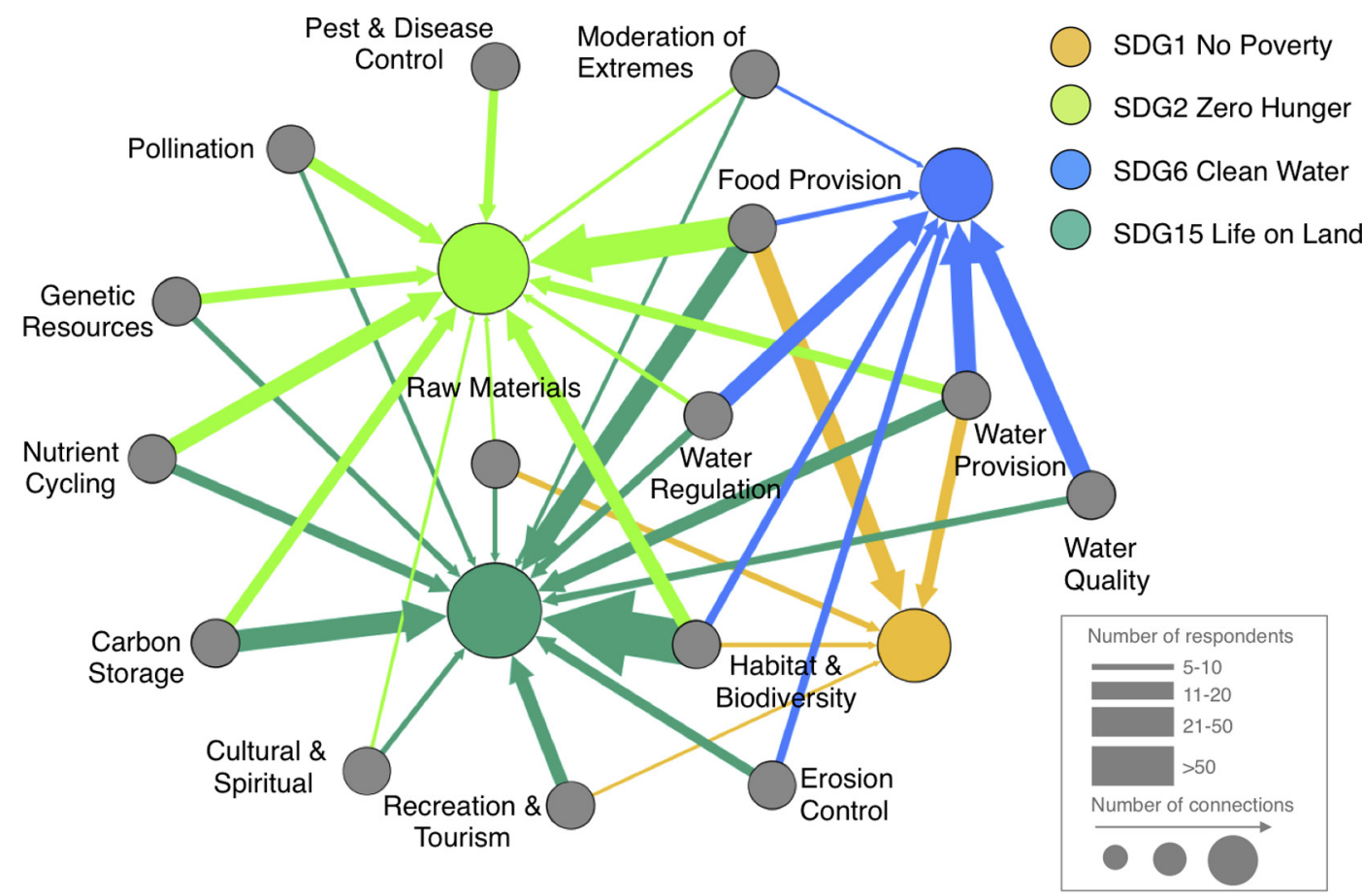

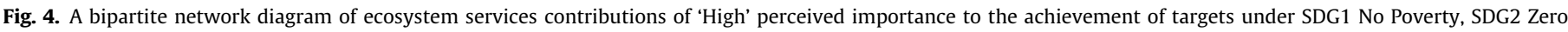

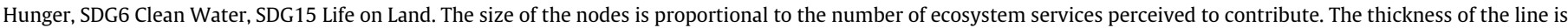
proportional to the number of respondents evaluating the linkage between the ecosystem service the SDG.

tively able to inform interactions between most of the remaining ecosystem services. However, for a subset of interactions between genetic resources, air quality, pollination, pest control and cultural \& spiritual services none of the reviewed tools are able to assess potential interactions.

\subsubsection{Correspondence of modelling tool capacity for SDG planning needs}

We compared the capacity of existing modelling tools to evaluate pairs of SDG-relevant ecosystem services. Tools that evaluate the magnitude, variability and direction of changes in pairs of 


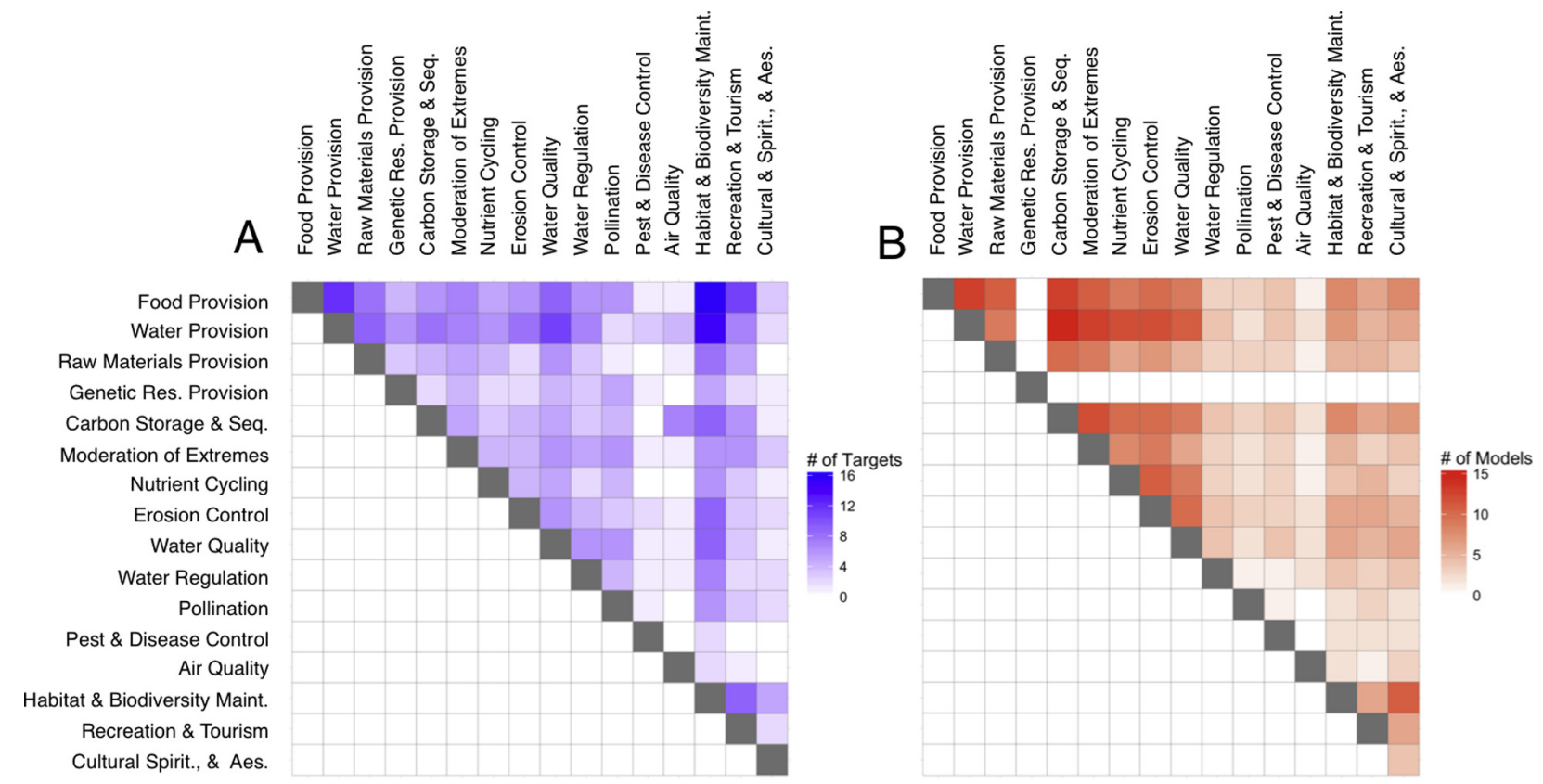



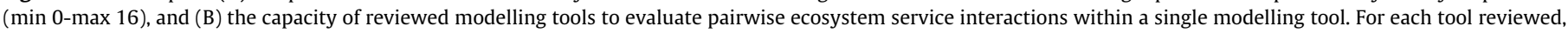

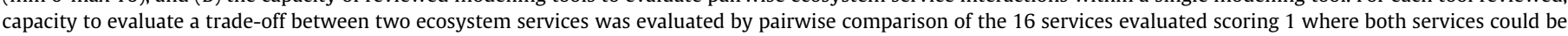



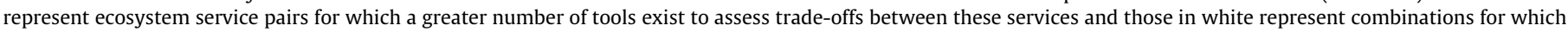

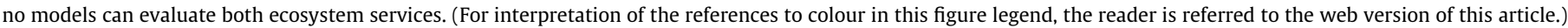

ecosystem services can be used to compare the impact of a planned intervention at the landscape scale. There was good correspondence between modelling tool capacities and the most common SDG-relevant ecosystem service combinations that we identified from survey responses (comparison of Fig. 5a and b). In particular, there were a high number of tools capable of estimating provision of food, water and raw materials, carbon storage \& sequestration, nutrient cycling and erosion, water quality and water regulation. Amongst these tools, there was also reasonable modelling capacity to assess habitat \& biodiversity maintenance as well as recreation services, but no models could to estimate change in genetic resource provisioning, perceived as potentially important for SDG2 and SDG6.

\section{Discussion}

\subsection{A perceived role for ecosystem services to support the SDGs}

The Sustainable Development Goals represent an agenda to end poverty and increase prosperity while protecting the planet from degradation (UN, 2015a). Biodiversity and ecosystem conservation form the basis of two SDG goals (14 \& 15), and their contribution to ecosystem services and human well-being underpins the achievement of all other goals (ICSU ISSC, 2015). In this paper we present results from a large survey of ecosystem service and development experts of their perceptions of ecosystem service contribution to the attainment of the SDGs. We concomitantly review the capacity for spatial modelling tools to support landscape planning by modelling services perceived to contribute to the SDGs. Despite the large size of the survey and high number of perceived contributions of ecosystem services to targets, our assessment is likely incomplete due to unbalanced representation of respondents across disciplines and uneven evaluation across goals (see discussion of survey limitations, Section 4.6). We present our results as a first attempt to map ES-T contributions and as a starting point for consideration of ecosystem services in national and landscape-level project design for the SDGs.

\subsection{Key findings}

The results of our survey highlight where ecosystem services are perceived contribute to the achievement of 41 SDG targets, and illuminate potential points of interactions across services. In particular, provision of food and water, maintenance of habitat \& biodiversity and carbon storage \& sequestration were identified as key services, each perceived to contribute to targets across seven or more SDG goals. These four ecosystem services were frequently linked to the same targets, along with water quality, water regulation, and recreation \& tourism. Because ecosystem services were evaluated in individually, interactions between services were not captured in survey responses. Many studies have shown that services are often bundled (Raudsepp-Hearne et al., 2010b; Renard et al., 2015). New land use changes can cause trade-offs within bundles to occur because services are produced at different rates and across different spatial scales, leading to differences in provision across communities and through time (Mulligan, 2015). Managing landscapes to maintain or enhance this suite of key ecosystem services, now and into the future, is likely to be particularly important for achieving multiple SDG targets in concert.

The alignment of survey responses and modelling tools suggest that there are significant entry points and resources to support landscape planning for the SDGs. The four cross-cutting services identified from expert responses (food provision, water provision, carbon storage and habitat \& biodiversity maintenance), plus erosion control, coincide with the most commonly mapped ecosystem services identified in a review of previous studies (Martínez-Harms and Balvanera, 2012). Furthermore, these services are most commonly mapped at the regional $\left(10^{3}-10^{5} \mathrm{~km}\right)$ and national scale (Martínez-Harms and Balvanera, 2012), making them particularly relevant for country-level evaluations and projects designed to 
Table 3

Review of the output metric capacities of selected landscape-level ecosystem service modelling tools.

\begin{tabular}{|c|c|c|c|c|c|c|c|c|c|c|c|c|c|c|c|c|c|}
\hline \multirow{2}{*}{$\begin{array}{c}\text { Ecosystem Service } \\
\text { Category }\end{array}$} & \multicolumn{3}{|c|}{$\begin{array}{c}\text { Provisioning } \\
\text { Services }\end{array}$} & \multicolumn{9}{|c|}{$\begin{array}{c}\text { Regulating } \\
\text { Services }\end{array}$} & \multirow{2}{*}{ 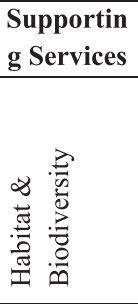 } & \multicolumn{3}{|c|}{$\begin{array}{l}\text { Cultural } \\
\text { Services }\end{array}$} & \multirow[b]{2}{*}{$\begin{array}{l}\text { Ease } \\
\text { of Use }\end{array}$} \\
\hline & $\begin{array}{l}* \\
\frac{*}{0} \\
0 \\
0 \\
1\end{array}$ & 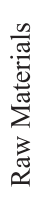 & 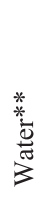 & 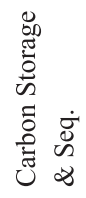 & 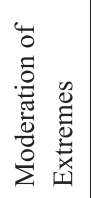 & 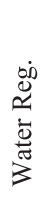 & 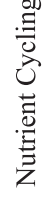 & 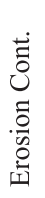 & 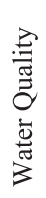 & 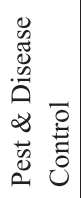 & 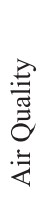 & 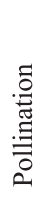 & & 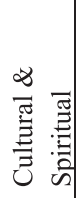 & 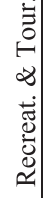 & $\frac{.0}{\frac{0}{0}}$ & \\
\hline \multicolumn{18}{|c|}{ Ecosystem Service Models } \\
\hline ARIES & & & & & & & & & & & & & & & & & Low \\
\hline BLOSM & & & & & & & & & & & & & & & & & Mod \\
\hline ClimSAVE & & & & & & & & & & & & & & & & & High \\
\hline Co\$ting Nature V2 & & & & & & & & & & & & & & & & & Mod \\
\hline InVEST & & & & & & & & & & & & & & & & & Mod \\
\hline LandscapeIMAGES & & & & & & & & & & & & & & & & & Mod \\
\hline OPAL & & & & & & & & & & & & & & & & & Mod \\
\hline RIOS & & & & & & & & & & & & & & & & & Mod \\
\hline SERVES & & & & & & & & & & & & & & & & & High \\
\hline SolvES & & & & & & & & & & & & & & & & & High \\
\hline UFORE/ i-Tree & & & & & & & & & & & & & & & & & High \\
\hline WHBET $^{\dagger}$ & & & & & & & & & & & & & & & & & High \\
\hline \multicolumn{18}{|c|}{ Ecosystem Process Models } \\
\hline AnnAGNP & & & & & & & & & & & & & & & & & Mod \\
\hline APEX & & & & & & & & & & & & & & & & & Low \\
\hline CENTURY & & & & & & & & & & & & & & & & & Low \\
\hline Kineros2 & & & & & & & & & & & & & & & & & Mod \\
\hline SWAT & & & & & & & & & & & & & & & & & Low \\
\hline TEM & & & & & & & & & & & & & & & & & Mod \\
\hline VIC & & & & & & & & & & & & & & & & & Mod \\
\hline WaterWorld & & & & & & & & & & & & & & & & & High \\
\hline \multicolumn{18}{|c|}{ Integrated Assessment Models } \\
\hline GLOBIOM & & & & & & & & & & & & & & & & & Low \\
\hline IMAGE & & & & & & & & & & & & & & & & & Low \\
\hline MIMES & & & & & & & & & & & & & & & & & Low \\
\hline Sum across Models & 16 & 10 & 19 & 17 & 5 & 11 & 14 & 14 & 14 & 4 & 2 & 3 & 11 & 5 & 8 & 8 & \\
\hline
\end{tabular}

Wildlife Habitat Benefits Estimation Tool.

"Food provisioning includes terrestrial crop and livestock production, fisheries and aquaculture.

${ }^{* *}$ Water provisioning includes both surface and groundwater provision.

address challenges presented by SDGs. The prevalence of research, funding and analysis on these ecosystem services in the literature suggests a greater awareness of their dynamics over others. This may have resulted in greater positive perceptions for their contribution to SDG targets, potentially at the expense of other ecosystem services that are less well researched and/or funded. Together these suggest that the role of less well-evaluated services in our survey should not be discounted, but rather that additional research is needed to establish their contribution to the multiple dimensions of human well-being captured in the SDGs.

\subsection{Ecosystem service-based management for synergistic SDG outcomes}

Our network analysis shows, based on expert perceptions, that SDG targets rarely dependent on a single ecosystem service and that most services are thought to contribute to targets across more than one goal (Fig. 3). This implies that policy-makers working to achieve the SDG targets reviewed here will need to manage for multiple ecosystem services (i.e. bundles) in order to realize these positive benefits. This will be particularly important for targets at the poverty-food-water-environment nexus where a large a number of targets were perceived to rely on common services. Diverse bundles of ecosystem services are generally associated with a large number of regulating services in addition to provisioning services (Raudsepp-Hearne et al., 2010b), and this is supported by perceptions captured in our survey. Carbon storage \& sequestration, water regulation and water quality were each judged to contribute to a wide range of targets.

In the survey, experts were asked if the "good management" of a given ecosystem service under consideration could help to attain the SDG target in question. Interactions of the ecosystem service with other services may or may not have been considered by respondents when providing an evaluation. It has been well documented that management for a single service often comes at the expense of many other services. Past efforts focused on increasing the supply of provisioning services to meet development objectives have frequently occurred at the expense of regulating services (MEA, 2005; Pereira et al., 2005). It is not possible from our results to infer whether experts considered such interactions in their evaluation, and if this affected their ranking for the importance of the service. It is possible that when interactions with other ecosystem 
services in a landscape are considered, that the importance of the contribution of any one service declines.

The adoption of an ecosystem service-based approach, by policy-makers and practitioners, which explicitly considers the interactions across services and goals, could help to better balance short-term efforts to increase provision of food, water and other material resources with the suite of regulating services supporting their long-term supply. We note that many technical and policyoriented SDG targets were not included in our survey and that policy makers will need to take a multi-pronged approach that includes legislative, economic and socio-technical initiatives alongside an ecosystem service-based approach to achieve the full spectrum of development priorities.

\subsection{The role of modelling tools to support SDG planning}

Making ecosystem services tangible to decision-makers through biophysical quantification is a critical step towards their successful inclusion into policies and planning frameworks (Cowling et al., 2008; Egoh et al., 2011). In their recent review of models and scenarios, IPBES highlights that models can be an effective means of articulating the relationships between nature, people and wellbeing, and allow the exploration of the projected consequences of alternative policy scenarios to inform decision-making (IPBES, 2016). For instance, while an intervention may increase service supply overall (e.g. water provision), it does not necessarily translate into improved SDG target attainment if access increases for a privileged group (e.g. commercial irrigators withdrawing reservoir water) at the expense of others targeted by the intervention (e.g. smallholder or downstream floodplain farmers). To date, a large number of ecosystem service models have been developed and are increasingly being used at local, national, and regional levels to inform landscape planning, priority setting and evaluation of investment trade-offs (Maes et al., 2012; Mulligan, 2015; Ruckelhaus et al., 2015; Ferrier et al., 2016).

Across the reviewed modelling tools, we found there was a stated capacity to estimate nearly all ecosystem services except for genetic resource provisioning. At the time of review, most models estimated food and water provisioning in combination with an assortment of regulating and cultural services, though none was able to model them all, however this situation may have changed since carrying out the study. This suggests that a strong and possibly growing modelling capacity exists to support and inform interactions around key ecosystem services identified by experts, particularly interactions across SDG 1, 2, 6 and 15 . There was, however, generally lower stated capacity to evaluate animal-meditated services (pollination, pest \& disease control) and urban-related services (air pollution, moderation of extremes) or their trades-offs. This may be due to the inherent difficulty in predicting animal behaviours and a greater focus in the ecosystem services community and survey respondents on rural landscapes (although there is a growing literature on urban ecosystem services, e.g. Baró et al., 2014; Escobedo et al., 2011). These results complement and deepen the model review undertaken by IPBES (Ferrier et al., 2016) by looking at the specific ecosystem service interactions which models are capable of assessing and identify additional gaps in current tools that will need to be addressed in order to capture the range of service interactions expected in the SDGs. It was not, however, within the scope of this paper to assess the efficacy or accuracy of the tools' service estimations and additional review is needed to determine quality of model outputs.

\subsection{The perceived importance of habitat $\mathcal{E}$ biodiversity maintenance}

Of reviewed the ecosystem services, habitat \& biodiversity maintenance was most frequently evaluated and, as a conse- quence, had the greatest number of perceived contributions to attainment of SDG targets. Many of these perceived contributions were linked to targets under SDG 14 (Life Below Water) and SDG 15 (Life on Land) for the direct protection of species and the environment. A significant number were also thought to contribute to six other SDGs ranging from No Poverty (SDG1) to Sustainable Cities (SDG11). In many ecosystem service frameworks, biodiversity is often not considered an service sensu stricto (Naeem et al., 2002), but rather the interactions amongst species and their environment are the means by which other ecosystem services are produced (Balvanera et al., 2006; Cardinale et al., 2012; Duncan et al., 2015; Ricketts et al., 2016). There is growing evidence that greater levels of biodiversity support enhanced and/or more stable provision of other services (e.g. insect diversity - pollination, Garibaldi et al., 2013; crop diversity - yield, Smith et al., 2008; tree diversity - carbon storage, Poorter et al., 2015). Where species conservation was not the primary objective of the SDG target, we expect that many of the contributions from habitat \& biodiversity maintenance identified by experts were perceived as indirect in nature.

This dual contribution of habitat \& biodiversity maintenance to the SDGs, both direct and indirect, may pose a significant challenge for its accurate consideration in landscape management plans. While many of the reviewed modelling tools had the capacity to evaluate the service, this was achieved primarily by calculating the change in area of land cover. None of the models reviewed included an explicit modelling of biodiversity as an outcome of landscape change. Previous reviews of ecosystem service models (Crossman et al., 2013; Martínez-Harms and Balvanera, 2012) have also found that despite a long disciplinary history of modelling habitat suitability, population dynamics and biodiversity hotspots in the ecological and environmental sciences, methods to model biodiversity change remain less common in the ecosystem service literature (Crossman et al., 2013). Few, if any models, incorporate both direct impact of land use changes on biodiversity, and its indirect impact on the provision of other services. This is a critically missing component in our ability to accurately assess the impacts of landscape change on ecosystem service provision. There is a need to develop a more mechanistic inclusion of biodiversity's indirect role in estimating other ecosystem functions and services (e.g. Duncan et al., 2015, Gonzalez et al., 2009) to better appreciated its role in achieving the SDGs.

\subsection{Survey limitations}

Our survey acknowledged a priori a role for ecosystem services in achieving the SDGs and sought out expert knowledge to identify where management of ecosystem services could most contribute to specific development targets. We observed a broad tendency for respondents to agree that ecosystem services could contribute to almost all of the 44 selected targets evaluated. This bias is not unexpected given respondents' background, self-selection to take the survey, and the fact that respondents were asked to select their own areas of expertise. We found that food provisioning and habitat \& biodiversity maintenance services and SDG 2, 6 and 15 were most commonly selected to evaluate (SM4a), likely reflecting the larger number of survey respondents from agriculture, ecology, natural resource management and sustainability sciences (SM5). We used a snowballing technique to access this "hidden community" of ecosystem service and development experts (Sudman and Kalton, 1986), an approach that can also introduce bias into the sample. In general, individuals receiving the survey are more likely to forward it on to colleagues within their own social network who may share common understandings and perspectives, thus amplifying certain perceptions over others. As a result, this approach is effective in identifying where there is strong agreement in understanding around particular ecosystem services, but 
can result in other perspectives or services being under represented.

This sampling approach also may explain why certain ES-T combinations were evaluated much more frequently than others, resulting in under-evaluation of certain sets of ecosystem services or goals. For example, a large body of literature exists on the role of nutrient cycling and erosion control on downstream coastal water quality (Barbier, 2012; Carpenter et al., 1998; Vitousek et al., 1997). However, the contribution of these services to SDG14.1 to prevent and significantly reduce marine pollution of all kinds, in particular from land-based activities, including marine debris and nutrient pollution, were evaluated as having only 'Weak' expert support because the target was assessed by less than 5 respondents and only $5 \%$ of our respondent pool worked on coastal and marine systems (SM5). Thus, we urge a strong degree of caution before excluding the possibility of ES-T combinations not classified as having 'Strong' support, as the sampling design is highly susceptible to underevaluation. Additional research and review of current literature is needed on these under-evaluated linkages to broaden and better evaluate the evidence base for the potential contribution of these ecosystem services to SDG targets.

Finally, since experts were asked to evaluate ecosystem services on an individual basis, we cannot predict from experts' responses how two or more services contributing to a common target are expected to interact. Additional surveys and reviews of the literature are needed to estimate if these interactions are likely to be positive ("indivisible, reinforcing, enabling"), neutral ("consistent") or negative ("constraining, counteracting or cancelling") using a scale such as Nilsson et al. (2016).

\subsection{Ways forward}

We recognize that ecosystem service management alone will be insufficient to achieve the ambitious SDG agenda. Ecosystem service management will need to be paired with complementary technologies and socio-institutional-based solutions in order to achieve targets over the short SDG timespan (2015-2030). For example, achieving clean water targets under SDG6 will require a combination of installing water treatment plants alongside catchment land cover and land use management. Similarly, efforts to eradicate malaria and other emerging neotropical diseases (SDG3, target 3.3) will require a suite of tools from land cover and landuse management for pest \& disease control, to insecticide-treated bed nets and national health programs to educate and treat affected communities. In many instances socio-institutional solutions may offer cheaper and quicker solutions to pressing challenges, as they require less infrastructure to implement and can tackle some of the root causes of the problem (Cartwright et al., 2013). However, all too often ecosystem services are undervalued in planning which can lead to ineffective solutions in the long term, e.g. levying of the Mississippi river to prevent flooding has altered the hydrology sustaining the surrounding wetlands needed to buffer the coastline against storm surges (Day et al., 2007). Both socioinstitutional and technology-based solutions should be planned in concert rather than in competition with ecosystem-based approaches at the outset of policy development to identify the most effective and enduring solutions to achieve national development aims while avoiding unforeseen trade-offs with other goals.

To facilitate uptake of ecosystem service-based approaches for the SDGs, new output indicators that speak directly to the metrics tracked in the SDG framework would also be useful (Ferrier et al., 2016). Indicators which report ecosystem service outcomes in terms of land area or number of people affected (as is done in WaterWorld and Co\$tingNature), malnutrition rates, and proportion of demographic groups with access to specific resources are likely more intuitive and compelling for decision-makers than traditional biophysical or economic indicators (e.g. tons of carbon, $\mathrm{m}^{3}$ of water, avoided costs). Small changes to current model outputs, for example translating sediment erosion into avoided degradation or crop production into calories and micronutrient availability, are possible and would provide entry points with policymakers on the value of ecosystem service-based approaches. However, including these "human well-being" indicators in model outputs adds another 'step' in the chain of estimation from ecosystem function, service supply, and service use to human well-being, requiring greater model simplification and potentially increasing uncertainty and errors.

\section{Conclusions}

Our survey results reflect broad support from ecosystem service and development experts for the role of ecosystem services in supporting the SDGs. While we were not able to assess the contribution of all services to all SDG targets evenly, we identify four ecosystem services that are perceived to make important contributions to achieving targets across 12 different goals and identify additional services expected to contribute to more select sets of targets. A large number of modelling tools are already available to support policy-makers in their efforts to incorporate ecosystem service approaches, which can increase the chances of achieving the ambitions set out in the SDGs. By distilling expert perceptions and identifying tools, we help chart a path forward for the considerations of ecosystem service and management into local and national development policy plans.

\section{Acknowledgements}

This research was conducted by the Making Ecosystems Count in the Sustainable Development Goals expert working group supported in part by Science for Nature and People Partnership (SNAPP), a partnership of The Nature Conservancy, the Wildlife Conservation Society and the National Center for Ecological Analysis and Synthesis (NCEAS) at University of California, Santa Barbara, and with funding from the CGIAR programs on Water Land \& Ecosystems, and Policy, Institutions \& Markets and The Christensen Fund [grant number 2103-6712225, 2013-2016] and The Christensen Fund [grant number 2013-6712225]. NCEAS, TNC, and the CGIAR sponsored staff salaries and travel of workshop participants during the duration of the project. We received ethical approval for the survey from project partner King's College London, ethics number MR/15/16-229. We heartily thank all the anonymous survey respondents, and consultation and workshop participants for their contribution to this project as well as A.G. for his very thoughtful and supportive input throughout the process.

\section{Appendix A. Supplementary data}

Supplementary data associated with this article can be found, in the online version, at https://doi.org/10.1016/j.ecoser.2017.10.010.

\section{References}

Balvanera, P., Pfisterer, A.B., Buchmann, N., He, J.S., Nakashizuka, T., Raffaelli, D., Schmid, B., 2006. Quantifying the evidence for biodiversity effects on ecosystem functioning and services. Ecol. Lett. 9 (10), 1146-1156.

Barbier, E.B., 2012. Progress and challenges in valuing coastal and marine ecosystem services. Rev. Environ. Econ. Policy 6 (1), 1-19.

Baró, F., Chaparro, L., Gómez-Baggethun, E., Langemeyer, J., Nowak, D.J., Terradas, J., 2014. Contribution of ecosystem services to air quality and climate change mitigation policies: the case of urban forests in Barcelona, Spain. Ambio 43 (4), 466-479. 
Bastian, M., Heymann, S., Jacomy, M., 2009. Gephi: an open source software for exploring and manipulating networks. In: International AAAI Conference on Weblogs and Social Media.

Cardinale, B.J., Duffy, J.E., Gonzalez, A., Hooper, D.U., Perrings, C., Venail, P., Narwani, A., Mace, G.M., Tilman, D., Wardle, D.A., Kinzig, A.P., 2012. Biodiversity loss and its impact on humanity. Nature 486 (7401), 59-67.

Carpenter, S.R., Caraco, N.F., Correll, D.L., Howarth, R.W., Sharpley, A.N., Smith, V.H. 1998. Nonpoint pollution of surface waters with phosphorus and nitrogen. Ecol Appl. 8 (3), 559-568.

Cartwright, A., Blignaut, J., De Wit, M., Goldberg, K., Mander, M., O’Donoghue, S. Roberts, D., 2013. Economics of climate change adaptation at the local scale under conditions of uncertainty and resource constraints: the case of Durban, South Africa. Environ. Urban. 25 (1), 139-156.

Cowling, R.M., Egoh, B., Knight, A.T., O’Farrell, P.J., Reyers, B., Rouget, M., Roux, D.J. Welz, A., Wilhelm-Rechman, A., 2008. An operational model for mainstreaming ecosystem services for implementation. Proc. Natl. Acad. Sci. 105 (28) 9483-9488.

Crossman, N.D., Burkhard, B., Nedkov, S., Willemen, L., Petz, K., Palomo, I., Drakou, E. G., Martín-Lopez, B., McPhearson, T., Boyanova, K., Alkemade, R., 2013. A blueprint for mapping and modelling ecosystem services. Ecosyst. Services 4, 4 14.

Day Jr., J.W., Boesch, D.F., Clairain, E.J., Kemp, G.P., Laska, S.B., Mitsch, W.J., Orth, K. Mashriqui, H., Reed, D.J., Shabman, L., Simenstad, C.A., Streever, B.J., Twilley, R. R., Watson, C.C., Wells, J.T., Whigham, D.F., 2007. Restoration of the Mississippi delta: lessons from hurricane Katrina and Rita. Science 315 1679-1684.

DeClerck, F.A., Jones, S., Attwood, S., Bossio, D., Girvetz, E., Chaplin-Kramer, R, Enfors, E., Fremier, A.K., Gordon, L.J., Kizito, F., Lopez-Noriega, I., Matthews, N., McCartney, M., Meacham, M., Noble, A., Quintero, M., Remans, R., Soppe, R. Willemen, L., Wood, S.L.R., Zhang, W., 2016. Agricultural ecosystems and their services: the vanguard of sustainability? Curr. Opin. Environm. Sustain. 23, 92 99.

Díaz, S., Demissew, S., Carabias, J., Joly, C., Lonsdale, M., Ash, N., Larigauderie, A. Adhikari, J.R., Arico, S., Báldi, A., Bartuska, A., 2015. The IPBES conceptual framework-connecting nature and people. Curr. Opin. Environm. Sustain. 14 $1-16$.

Duncan, C., Thompson, J.R., Pettorelli, N., 2015. The quest for a mechanistic understanding of biodiversity-ecosystem services relationships. Proc. R. Soc. B 282 (1817), 20151348

Egoh, B.N., Reyers, B., Rouget, M., Richardson, D.M., 2011. Identifying priority areas for ecosystem service management in South African grasslands. J. Environ. Manage. 92 (6), 1642-1650.

Escobedo, F.J., Kroeger, T., Wagner, J.E., 2011. Urban forests and pollution mitigation: analyzing ecosystem services and disservices. Environ. pollut. 159 (8), 2078-2087.

Ferrier, S., Ninan, K.N. Leadley, P., Alkemade, R., Acosta, L.A., Akcakaya, H.R. Brotons, L., Cheun, W.W.L., Christensen, V., Harhash, K.A., Kabubo-Mariara J., Lundquist, C., Obersteiner, M., Pereira, H.M. Peterson, G. Pichs-Madruga, R., Ravindranath, N., Rondinini, C., Wintle, B.A., 2016. The methodological assessment report on scenarios and models of biodiversity and ecosystem services. Secretariat of the Intergovernmental Science-Policy Platform on Biodiversity and Ecosystem Services, Bonn, Germany, pp. 348.

Food and Agriculture Organization of United Nations (FAO), 2015. The State of Food Insecurity in the World 2015: Meeting the 2015 international hunger targets: taking stock of uneven progress. Economic and Social Development Department of the United Nations Food and Agriculture Organization, Rome, Italy.

Folke, C., Biggs, R., Norström, A., Reyers, B., Rockström, J., 2016. Social-ecological resilience and biosphere-based sustainability science. Ecol. Soc. 21 (3). Online.

Garibaldi, L.A., Steffan-Dewenter, I., Winfree, R., Aizen, M.A., Bommarco, R. Cunningham, S.A., Kremen, C., Carvalheiro, L.G., Harder, L.D., Afik, O., Bartomeus, I., 2013. Wild pollinators enhance fruit set of crops regardless of honey bee abundance. Science 339 (6127), 1608-1611.

Gonzalez, A., Mouquet, N., Loreau, M., 2009. Biodiversity as spatial insurance: the effects of habitat fragmentation and dispersal on ecosystem functioning. In Naeem, S., Bunker, D.E., Hector, A., Loreau, M., Perrings, C. (Eds.), Biodiversity, Ecosystem Functioning and Ecosystem Services: An Ecological and Economic Perspective. Oxford University Press Inc., New York, NY.

Griggs, D., Stafford Smith, M., Rockström, J., Öhman, M.C., Gaffney, O., Glaser, G. Kanie, N., Noble, I., Steffen, W., Shyamsundar, P., 2014. An integrated framework for sustainable development goals. Ecol. Soc. 19 (4), 49.

Guerry, A.D., Polasky, S., Lubchenco, J., Chaplin-Kramer, R., Daily, G.C., Griffin, R. Ruckelshaus, M.H., Bateman, I.J., Duraiappah, A., Elmqvist, T., Feldman, M.W., Folke, C., Hoekstra, J., Kareiva, P., Keeler, B., Li, S., McKenzie, E., Ouyang, Z., Reyers, B., Ricketts, T., Rockström, J., Tallis, H., Vira, B., 2015. Natural capital informing decisions: from promise to practice. Proc. Natl. Acad. Sci. 112, 7348 7355.

ICSU ISSC, 2015. Review of the Sustainable Development Goals: The Science Perspective. Paris: International Council for Science (ICSU). Accessed March 23rd 2016. Available from: http://www.icsu.org/publications/reports-and reviews/review-of-targets-for-the-sustainable-development-goals-thescience-perspective-2015/SDG-Report.pdf

International Panel on Biodiversity and Ecosystem Services (IPBES), 2016 Decision and scoping report for the IPBES global assessment on biodiversity and ecosystem services. Accessed November 9th 2016. Available from: http://www.ipbes.net/sites/default/files/downloads/pdf/Scoping_Global\%20 assessment.pdf
Landscapes for People Food and Nature (LPFN), 2015. Achieving the SDGs through Integrated Landscape Management. White Paper. Accessed Jan 8th 2016. Available from: http://ecoagriculture.org/wp-content/uploads/2015/12/LPFN_ WhitePaper_112415c_lowres.pdf

Maes, J., Paracchini, M.L., Zulian, G., Dunbar, M.B., Alkemade, R., 2012. Synergies and trade-offs between ecosystem service supply, biodiversity, and habitat conservation status in Europe. Biol. Conserv. 155, 1-12.

Martínez-Harms, M.J., Balvanera, P., 2012. Methods for mapping ecosystem service supply: a review. Int. J. Biodivers. Sci. Ecosyst. Services Manage. 8 (1-2), 17-25.

Mbow, C., Van Noordwijk, M., Prabhu, R., Simons, T., 2014. Knowledge gaps and research needs concerning agroforestry's contribution to sustainable development goals in Africa. Curr. Opin. Environm. Sustain. 6, 162-170.

Millennium Ecosystem Assessment (MEA), 2005. Ecosystems and Human Wellbeing: Synthesis vol 5 Online: http://www.millenniumassessment. org/documents/document.356.aspx.pdf

Mulligan, M., 2015. Trading off agriculture with nature's other benefits, spatially. In: Zolin, C.A., Rodrigues, R.deA.R. (Eds.), Impact of Climate Change on Water Resources in Agriculture. CRC Press, Boca Raton, pp. 184-204.

Naeem, S., Loreau, M., Inchausti, P., 2002. Biodiversity and ecosystem functioning: the emergence of a synthetic ecological framework. In: Loreau, M., Naeem, S., Inchausti, P. (Eds.), Biodiversity and Ecosystem Functioning: Synthesis and perspectives. Oxford University Press, Oxford, p. 294.

Naeem, S., Duffy, J.E., Zavaleta, E., 2012. The functions of biological diversity in an age of extinction. Science 336 (6087), 1401-1406.

Nilsson, M., Griggs, D., Visbeck, M., 2016. Policy: map the interactions between Sustainable Development Goals. Nature 534, 320-322.

Norström, A., Wetterstrand, H., Schultz, M., Elmqvist, T., Cornell, S., Öhman, M.C., Daw, T., Moberg, F., Persson, A., Peterson, G. and J. Rockström. 2014. Issue brief: Integrating social-ecological resilience, biodiversity and ecosystem services into the sustainable development goals. A contribution of Stockholm Resilience Centre and ICSU (International Council for Science) for the 8th Session of the UN General Assembly Open Working Group on Sustainable Development Goals, New York, pp. 4-8.

Pereira, H.M., Reyers, B., Watanabe, M., Bohensky, E., Foale, S., Palm, C., Espaldon, M. V., Armenteras, D., Tapia, M., Rincon, A., Lee, M.J., Patwardhan, A., Gomes, I., 2005. Condition and trends of ecosystem services and biodiversity. In: Capistrano, D. (Ed.), Millennium Ecosystem Assessment. Island Press, Washington, USA, pp. 171-203.

Poorter, L., Sande, M.T., Thompson, J., Arets, E.J.M.M., Alarcón, A., Álvarez-Sánchez, J., Ascarrunz, N., Balvanera, P., Barajas-Guzmán, G., Boit, A., Bongers, F., 2015. Diversity enhances carbon storage in tropical forests. Glob. Ecol. Biogeogr. 24 (11), 1314-1328.

Raudsepp-Hearne, C., Peterson, G.D., Tengö, M., Bennett, E.M., Holland, T., Benessaiah, K., MacDonald, G.K., Pfeifer, L., 2010a. Untangling the environmentalist's paradox: why is human well-being increasing as ecosystem services degrade? Bioscience 60 (8), 576-589.

Raudsepp-Hearne, C., Peterson, G.D., Bennett, E.M., 2010b. Ecosystem service bundles for analyzing tradeoffs in diverse landscapes. Proc. Natl. Acad. Sci. 107 (11), 5242-5247.

Raworth, K., 2012. A Safe and just space for humanity: Can we live within the doughnut? Oxfam Discussion Paper. Oxfam GB, Oxford.

Renard, D., Rhemtulla, J.M., Bennett, E.M., 2015. Historical dynamics in ecosystem service bundles. Proc. Natl. Acad. Sci. 112 (43), 13411-13416.

Ricketts, T.H., Watson, K.B., Koh, I., Ellis, A.M., Nicholson, C.C., Posner, S., Richardson, L.L., Sonter, L.J., 2016. Disaggregating the evidence linking biodiversity and ecosystem services. Nat. Commun. 7, 13106.

Rockström, J., Falkenmark, M., 2015. Agriculture: increase water harvesting in Africa. Nature 519 (7543), 283-285.

Ruckelshaus, M., McKenzie, E., Tallis, H., Guerry, A., Daily, G., Kareiva, P., Polasky, S., Ricketts, T., Bhagabati, N., Wood, S.A., Bernhardt, J., 2015. Notes from the field: Lessons learned from using ecosystem service approaches to inform real-world decisions. Ecol. Econ. 115, 11-21.

Smith, R.G., Gross, K.L., Robertson, G.P., 2008. Effects of crop diversity on agroecosystem function: crop yield response. Ecosystems 11 (3), 355-366.

Stafford-Smith, M., 2014. UN sustainability goals need quantified targets. Nature 513 (7518), 281

Steffen, W., Richardson, K., Rockström, J., Cornell, S.E., Fetzer, I., Bennett, E.M., Biggs, R., Carpenter, S.R., de Vries, W., de Wit, C.A., Folke, C., 2015. Planetary boundaries: Guiding human development on a changing planet. Science 347 (6223), 1259855.

Sudman, S., Kalton, G., 1986. New developments in the sampling of special populations. Ann. Rev. Sociol. 12, 401-429.

The Economics of Ecosystems and Biodiversity (TEEB), 2010. Ecosystem Services Typology. The Economics of Ecosystems and Biodiversity: Ecological and Economic Foundations. In: Pushpam Kumar (ed.), EarthScan, London and Washington. Accessed on October 28th 2016, Available from: http:// www.teebweb.org/resources/ecosystem-services/

UN Secretary-General, 2014. The road to dignity by 2030: Ending poverty, transforming all lives and protecting the planet. Synthesis report of the Secretary-General on the Post-2015 Agenda. A/69/700, Accessed January 26th 2015, Available from: http://www.un.org/ga/search/view_doc.asp?symbol=A/ 69/700\&Lang=E.

United Nations, 2015a. Millennium Development Goals Report 2015. United Nations. Accessed December 3rd 2016, Available from: http://www.un.org/ millenniumgoals/2015_MDG_Report/pdf/MDG\%202015\%20rev\%20\%28July\% 201\%29.pdf. 
United Nations, 2015b. Transforming our world: the 2030 Agenda for Sustainable Development A/RES/70/1. Accessed January 21st 2016, Available from: https://sustainabledevelopment.un.org/content/documents/21252030\% 20Agenda\%20for\%20Sustainable\%20Development\%20web.pdf

United Nations Development Program (UNDP), 2015. Human Development Report: Work for Human Development. United Nations Development Program. Accessed September 18th 2016, Available from: http://hdr.undp.org/sites/ default/files/2015_human_development_report_1.pdf

Villa, F., Bagstad, K.J., Voigt, B., Johnson, G.W., Portela, R., Honzák, M., Batker, D., 2014. Methodology for adaptable and robust ecosystem services assessment. Plos One 9, e91001.
Vitousek, P.M., Aber, J.D., Howarth, R.W., Likens, G.E., Matson, P.A., Schindler, D.W. Schlesinger, W.H., Tilman, D.G., 1997. Human alteration of the global nitrogen cycle: sources and consequences. Ecol. Appl. 7 (3), 737-750.

Wood, S.L.R., DeClerck, F.A., 2015. Ecosystems and human well-being in the Sustainable Development Goals. Front. Ecol. Environ. 13 (3), 123.

World Economic Forum (WEF), 2016. Insight Report: The Global Gender Report World Economic Forum. Accessed June 14th 2016, Available from: https:// www.weforum.org/reports/the-global-gender-gap-report-2016. 